\title{
Distal femur kaynamamaları ve tedavisi
}

\section{Distal femur non-unions and their treatment}

\author{
İsmail Karasoy ${ }^{1}$, Erman Ceyhan², Ertuğrul Akşahin ${ }^{3}$ \\ ${ }^{1}$ Gümüşhane Devlet Hastanesi Ortopedi ve Travmatoloji Servisi, Gümüşhane \\ ${ }^{2}$ Ankara Numune Hastanesi, Ortopedi ve Travmatoloji Kliniği, Ankara \\ ${ }^{3}$ Ankara Medical Park Hastanesi, Ortopedi ve Travmatoloji Bölümü, Ankara
}

\begin{abstract}
Distal femur kırıkları, femurun distal $15 \mathrm{~cm}$ uzunluğundaki bölgesini içine alır. Bunlar, tüm kırıkların yaklaşık \%1'ini ve femur kırıklarının \%3-6'sını oluşturmaktadır. Distal femur kırıklarının tipi, eşlik eden diğer faktörlerle beraber, tedavi tipinin ve kullanılacak tespit materyallerinin tercihi açısından önemlidir. Distal femur kırıkları, birçok ortopedik tespit materyaliyle beraber (kilitli plaklar, intramedüller çiviler, kondiler vidalar ve kamalı plaklar) açık veya kapalı redüksiyon sonrası tespit edilebilmektedir. Kilitli kompresyon plakları, günümüzde distal femur kırıkları için en sık tercih edilen yöntemdir. Literatürde distal femur kırığı cerrahisi sonrasında kaynamama ile alakalı birçok oran verilmekle birlikte, son yayımlanan bir seride, distal femur kırıkları sonrası kaynamama görülme sıklığı \%22 olarak verilmektedir. Distal femur kaynamama, hastanın hayat kalitesini ciddi oranda azaltan, uzun süreli sakatık hali yaratabilen ve tedavi edilmesi uzun süre alabilen komplike bir durumdur. Hal böyleyken, distal femur kaynamama ile alakalı olarak net bir tedavi algoritması bulunmamaktadır. Bu nedenle, distal femur kaynamamaya yol açan durumlar ortaya konulmalı ve bu duruma uygun tedavi şekli, gerekirse destek tedavileri de eklenerek seçilmelidir.
\end{abstract}

Anahtar sözcükler: distal femur kırıkları; kilitli plak; kaynamama; periprostetik kırıklar
Distal femur fractures involve the distal $15 \mathrm{~cm}$ of femur. These fractures represent approximately $\% 1$ of whole fractures, and \%3-6 of femur fractures. The type of the distal femur fracture with accompanying factors is important in choosing the treatment modality and material. Distal femur fractures can be treated with many different implants (locked plates, intramedullary nails, condylar screws or blade plates) in open or closed manner. Nowadays, treatment with locked compression plates is the most preferred technique in dealing with distal femur fractures. Many different rates were reported in literature about distal femur nonunion, but in a recent study, distal femur nonunion after distal femur fracture is reported as \%22. Distal femur nonunion is a complicated situation that quietly decreases the life quality of a patient and creates long term disability, and this may take a long time to treat. Nevertheless, there is not any developed algorithm for the treatment of distal femur nonunion. Because of these factors in distal femur nonunion cases, primarily the reason of nonunion must be understood, and then proper treatment modality for the nonunion must be chosen with supporting treatments, if needed.

Key words: distal femur fractures; locked plate; nonunion; periprostetic fractures

\section{Distal Femur Kırıkları}

Distal femur kırıkları, femurun distal $15 \mathrm{~cm}$ uzunluğundaki bölgesini içine alır. Bunlar, tüm kırıkların yaklaşık \%1'ini ve femur kırıklarının \%3-6'sını oluşturmaktadır. ${ }^{[1]}$ Bu kırıklar bimodal dağılım göstermekte olup, genç yaş grubunda yüksek enerjili travmalardan sonra, geriatrik yaş grubunda ise düşük enerjili travmalardan sonra görülmektedir. ${ }^{[2]}$ Özellikle artan yaşlı nüfus ve total diz replasmanı cerrahisindeki artış periprostetik distal femoral kırıklarının da sıklığını arttırmaktadır. ${ }^{[3,4]}$
Distal femur kırıkları, kırı̆ıın etkilediği bölgeye göre ekstra-artiküler, kısmi artiküler ve intra-artiküler olarak sınıflandırılmaktadır. ${ }^{[5]}$ Bu bölge kırıklarının tedavisinde temel amaçlar, eklem yüzeyinin anatomik olarak restorasyonu, ekstremite diziliminin sağlanması ve erken mobilizasyondur. Bu nedenle, distal femur kırıklarının tipi, eşlik eden diğer faktörlerle beraber (kemik kaybı, açık kırık mevcudiyeti, eşlik eden diğer sistem patolojileri ve/veya kemik kırıkları, osteoporoz, kronik metabolik hastalıklar, yumuşak doku

- Illetişim adresi: Doç. Dr. Ertuğrul Akşahin, Ankara Medical Park Hastanesi, Ortopedi ve Travmatoloji, Ankara Tel: 0533 - 4820062 e-posta: ertugrul_aksahin@hotmail.com

- Geliș tarihi: 1 Kasım 2017 Kabul tarihi: 1 Kasım 2017 
kaybı vb.) tedavi tipinin ve kullanılacak tespit materyallerini tercihi açısından önemlidir.

Distal femur, anatomik olarak suprakondiler ve interkondiler olmak üzere iki bölgeye ayrılmaktadır. Hem üç planda da (koronal, sagittal, aksiyel) farklılık gösteren yapısı hem de büyük kas gruplarının yapışma yerleri nedeniyle ortaya çıkan redüksiyona engel kuvvetler, bu bölgenin cerrahisini daha da zorlaştırmaktadır. ${ }^{[2,6]}$

Kilitli kompresyon plakları, günümüzde distal femur kırıkları için en sık tercih edilen yöntemdir.[2,7] Antegrad ve retrograd çivileme, kamalı plaklar, dinamik kompresyon plakları da bazı kırık tipleri için tercih edilebilecek olsa da, kilitli kompresyon plaklarının hem klinik, hem radyolojik hem de biyomekanik açıdan daha iyi sonuçlar verdiği görülmektedir. ${ }^{[8]}$

\section{Distal Femur Kaynamama}

Distal femur kırıkları, birçok ortopedik tespit materyaliyle beraber (kilitli plaklar, intramedüller çiviler [iMÇ], kondiler vidalar ve kamalı plaklar), açık veya kapalı redüksiyon sonrası tespit edilebilmektedir. Literatürde distal femur kırı̆gı cerrahisi sonrasında kaynamama ile alakalı birçok oran verilmekle birlikte, son yayımlanan bir seride, distal femur kırıkları sonrası kaynamama görülme sıklığı \%22 olarak verilmektedir. ${ }^{[9]}$ Ayrıca, yaşlı bireylerde gelişen distal femur kırıkları sonrası gelişen kaynamama oranı da \%24 olarak bildirilmiştir. ${ }^{[10]}$

Distal femur kaynamama, hastanın hayat kalitesini ciddi oranda azaltan, uzun süreli sakatık hali yaratabilen ve tedavi edilmesi uzun süre alabilen komplike bir durumdur. Hastalar, sıklıkla ilgili ekstremiteye ağırlık verememe, kronik ağrı, azalmış diz eklem hareket açıklığı, aksiyel dizilim bozukluğu ve kısalık ile ilişkili şikâyetlerle başvurmaktadır. Distal femur kaynamamalarının yönetimi; distal parçanın küçük kalması, kötü kemik kalitesi ve kemik kaybıyla beraber kısalık, açılanma, rotasyonel deformite ve enfeksiyon varlığı nedeniyle sıklıkla karmaşık bir hal alır. ${ }^{[11]}$

\section{Kaynamama Nedenleri}

Kaynamama, birden fazla nedenden ortaya çıkabilir. Hastanın komorbid durumları, kullanılan implantın özellikleri, kırığın oluş mekanizması ve özellikleriyle beraber, cerrahi sırasında cerrahın yumuşak dokuya yaklaşımı süreci etkiler.

Kilitli plaklama, distal femoral kaynamama açısından ciddi predispozan bir faktördür. Henderson ve ark. çalışmalarında, kilitli plaklama sonrası kaynamama, gecikmiş kaynama, implant revizyonu veya greftleme gibi kaynama problemlerinin görülme sıklığının \%32 oranında olduğunu bildirmektedirler. ${ }^{[12]} \mathrm{Bir}$ diğer çalışmalarında da sadece kaynamama oranını $\% 20$ olarak vermektedirler. ${ }^{[13]}$ Hoffman ve ark. ise çalışmalarında, \%18'lik bir kaynamama oranından söz etmektedirler. ${ }^{[14]}$ Yazarlar, kilitli plakların daha gergin bir tespit oluşturması ve bu nedenle kırık hattında mikro-hareketi minimize etmesi nedeniyle kallus oluşumunu azalttı̆̆ını; bunun da kaynamama ile sonuçlandığı yönünde fikir beyan etmektedirler.

Kilitli plağın materyalinin de kaynamama lehinde etki ettiği yönünde çalışmalar mevcuttur. Rodriguez ve ark., kilitli plak yapılan 271 distal femur kırı̆̆ı hastasını incelediklerinde, paslanmaz çelik implantlarla opere edilen hastaların \%41'inde, titanyum implantlarla opere edilen hastaların ise \%10'unda kaynamama görüldüğünü belirterek, toplamda tüm olguların \%13,3'ünde kaynamama görüldügünü ve plak materyalinin kaynamama gelişmesi için bağımsız bir prediktör olduğunu ifade etmişlerdir. ${ }^{[15]}$ Bu çalışmanın aksine Lujan ve ark., geriye dönük inceledikleri 66 olguda, implant materyalinin kaynamamaya herhangi bir etkisinin olmadığını ifade etmişlerdir. ${ }^{[16]}$

Kullanılan implantın çeşidi de kaynamama üzerinde etkilidir. Kanada Ortopedi Topluluğu'nun 52 hasta üzerinde yaptığı randomize kontrollü çalışmada, dinamik kondiler vida (DCS) ve LISS (less invasive stabilization system) plak karşılaştırıldığında, DCS'nin \%91 oranında kaynama yüzdesi mevcutken, bu oran LISS plak grubunda $\% 52$ oranında görüldü. ${ }^{[17]}$ Yine Valier ve ark., geriye dönük olarak değerlendirdikleri kamalı plak ve kilitli kondiler plak (KKP) ile opere edilmiş hastalarda, kaynamama ve komplikasyon oranın KKP grubunda daha sık görüldüğünü bildirmişlerdir. ${ }^{[18]}$ LISS ve KKP'nin karşılaştırıldığı bir diğer çalışmada ise benzer oranlarda kaynamama olgusu görülmüştür. ${ }^{[9]}$

Ebraheim ve ark., 2013 yılına kadar distal femur kaynamama ile ilgili çalışmaları inceledikleri derlemede, sık kaynamama görülen olguların \%31,9'unun açık kırık olguları olduğunu, bunu da sırasıyla, kemik kaybı $(\% 22,1)$, implant yetmezliği $(\% 14,2)$ ve enfeksiyon $(\% 11,5)$ durumlarının takip ettiğini belirtmişlerdir. ${ }^{[19]}$ Garner ve ark. da özellikle çok parçalı metafizyel açık kırıklar sonrasında kaynamama oranının arttığını belirtmektedirler. ${ }^{[20]}$ Yazarlar, çok parçalı açık kırıkların da yumuşak dokuda oluşturduğu harabiyetin ve dolaşım bozukluğunun kaynamama için en önemli predispozan faktör olduğunu ifade etmektedirler. Bu yüzden, bu tür kırıkların cerrahisi sırasında aşırı yumuşak doku disseksiyonu yapılması, kaynamama lehine bir hareket olacaktır. Enfeksiyon varlığı da kaynamamaya neden olabilir. Bundan dolayı, kaynamama cerrahi tedavisinden önce kaynamama alanındaki enfeksiyon varlığı, hem radyolojik hem de laboratuvar tetkikleriyle 
değerlendirilmelidir. Şüphe varsa, derin doku biyopsisi yapılarak enfeksiyon varlığı araştırılabilir.

Morbid obezite, distal femur kırıkları sonrası kaynamama gelişimi açısından bir risk faktörü olarak görülmektedir. Ricci ve ark. çalışmalarında, yüksek VKi (Vücut Kitle Indeksi)'ye sahip olan hastaların daha çok implant yetmezliği geliştirmeye meyilli olduğunu ve bunun da bu hastalarda daha sık kaynamamaya neden olduğunu belirtmişlerdir. ${ }^{[7]}$

Ayrıca, sigara kullanımı, vitamin D eksikliği gibi kırık iyileşmesini etkileyecek durumların da varlığı kaynamama lehine sonuçlar ortaya çıkarabilmektedir.

\section{KLINIK DEĞERLENDIRME}

Distal femur kaynamama olgularında da, diğer kaynamama olgularında olduğu gibi, hastanın öyküsü, klinik muayenesi, komorbid durumların değerlendirilmesi, özellikle enfeksiyon varlığının araştırılması ve hastanın radyoloji değerlendirilmesinin yapılması gereklidir. Hastanın, standart iki yönlü femur grafilerinin, dizilim bozukluğunun değerlendirilebilmesi için aks grafilerinin ve kırık hattında hareket varlığının incelenebilmesi için stres grafilerinin çekilmesi gereklidir. Kaynamamanın radyolojik olarak kesin bir şekilde tanımlanabilmesi için bilgisayarlı tomografi tetkiki yapılmalıdır. Septik kaynamama düşünülen olgularda nükleer tıp incelemeleri de tanı algoritması içerisinde değerlendirilebilir.

\section{TEDAVi}

Distal femur kaynamama, bireyin hayat kalitesini ciddi anlamda bozacak ağrı ve azalmış diz hareketleriyle beraber gelişen bir maluliyet hali ortaya çıkartır. Bu duruma ek olarak, kaynamamayla beraber bu bölgede ciddi kemik kaybı, kemik kalitesinde bozulma (osteopeni), ciddi yumuşak doku skarı ve tercih edilmeyen kırık şekilleri görülebilir. ${ }^{[20]}$ Tedavisi zor olmakla birlikte, uygun tedavi şekli ve düzgün hasta uyumuyla birlikte tam iyileşme sağlanabilir. ${ }^{[21]}$ Her ne kadar bu olgular için belirli bir tedavi algoritması olmasa da, temelde kaynamamanın cinsine ve içerideki tespit materyaline göre literatürde tanımlanmış bir çok cerrahi yaklaşım bulunmaktadır.

\section{Plak Uygulamaları}

Distal femur kaynamamalarında sıklıkla kullanılan cerrahi yöntemlerden biri plakla tespittir. Chapman ve ark., 15 'i kırık sonrası, üçü osteotomi sonrası plak tespiti yapılmış ve sonrasında kaynamama nedeniyle plak tespiti ile otolog greftleme yapılan 18 hastayı (13 hastaya çift plak, beş hastaya tek plak) geriye dönük olarak değerlendirdikleri çalışmalarında \%100 kaynama bildirdiler. On sekiz hastanın dokuzuna primer kaynamama cerrahisi sonrasında ek işlemler yapılmıştı. ${ }^{[22]}$ Bellabarba ve ark., indirekt redüksiyon ve plak tespiti yaptıkları 20 hastayı (13 hastaya kamalı plak, dört hastaya kondiler destek plağı, üç hastaya kilitli kompresyon plağı) inceledikleri çalışmalarında \%100 kaynama bildirdiler. Bu çalışmadaki yedi atrofik ve altı oligotrofik kaynamama olgusu otolog greftlendi. ${ }^{[11]}$ Aynı ekibin iMÇ sonrası kaynamama gelişmiş ve sekizi distal femoral kaynamama olan 23 femur kaynamama olgusunda, iki hastayı implant yetmezliğine bağlı olarak tekrar opere etmelerine rağmen, indirekt redüksiyon ve lateralden plaklama sonrasında, ortalama 17 hafta sonunda \%100 kaynama sağlanmış. ${ }^{[23]}$ Wang ve ark., 13 hastada strut allogreft ve otogreft ile birlikte yaptıkları kamalı plak osteosentez sonrasında, ortalama beş ay içinde tüm hastalarda kaynama elde ettiklerini bildirdiler. Takip sürecinde, bu hastaların ikisine bir, dördüne de iki adet ek işlem yapıldığı belirtilmiştir. Yazarlar, bu hızlı kaynamadan, stabil internal tespite ek yapılan strut greft desteğinin sorumlu olduğunu ifade etmektedirler. ${ }^{[24]}$ Kanakeshwar ve ark. bu tekniği modifiye ederek, strut allogrefti kaynamama alanı mediyaline intramedüller mahiyette yerleştirip, otogreft ile birlikte kamalı plak osteosentez yaptılar. Bu çalışmaya, en az iki kez kaynamama nedeniyle opere edilmiş 22 dirençli distal femur kaynamama hastasını dahil ettiler. Çalışma sonucunda tüm hastalarda kaynama elde ettikleri bu teknikte, strut grefti mediyal intramedüller alana yerleştirmekle kaynamamanın temel sorunlarından olan metafizyel mediyal kemik kaybını düzeltebilmeyi amaçladıklarını ve bu amaca ulaştıklarını belirttiler. ${ }^{[25]}$ Gardner ve ark., 31 olguluk serilerinde, kamalı plak, dinamik kompresyon vidası, kilitli plak kullanarak ve tüm olguları greftleyerek (\%71 iliak otolog, \%29 demineralize kemik matriksi) \%97 oranında kaynama bildirdiler. Otuz bir hastanın 30'unda ek bir işleme gerek kalmadan kaynama elde ettiklerini, kaynamayan tek olgularında da menteşeli diz protezi kullanarak kurtarma işlemi gerçekleştirdiklerini ifade ettiler. ${ }^{[20]}$ Amoraso ve ark., kamalı plak osteosentez ve greftleme yaptıkları 32 hastanın 27'sinde (\%92,7) kaynama bildirdiler. ${ }^{[26]}$

Holzman ve ark. ise kendilerine göre bir tedavi algoritması oluşturarak, bunu 22 hastada 23 distal femur kaynamama olgusuna uyguladılar. Tedavinin temeli, lateral kilitli plağın durumuna göre belirlendi. Lateral plak kırı/instabil ise, plak değiştirilerek lateralden tekrar kilitli plak uygulaması yapıldı. Eğer lateral plak stabil olmasına rağmen kaynama elde edilmemişse, mediyalden ek bir kilitli plak konuldu (primer kaynamama 
olan lateral kilitli plak hastalarında da). Her iki durumda da otolog kemik grefti kullanıldı (altı hastada ek olarak kemik morfojenik protein kullanılmış). Çalışmalarında, 16 hastaya tek basamaklı, yedi hastaya iki basamaklı tedavi uygulayarak, \%95,2 oranında kaynama elde ettiklerini belirttiler. Enfekte hastaları olmamakla birlikte, algoritmada enfekte hastalar için plak çıkarıldıktan sonra enfeksiyon tablosu ortadan kaldırıldıktan sonra lateral kilitli plak uygulanması, kaynamama mevcudiyetinde ise enfekte olmayan hastalara uygulanan şablondan devam edilmesini önerdiler. Stabil lateral tespit varlığında, ek mediyal tespit ve otolog greftlemenin tercih edilebilir başarılı bir sonuç olduğunu belirttiler. ${ }^{[27]}$ Ebraheim ve ark. çalışmalarında, 14 hastanın 11 'inde lateral plağı yerinde bırakıp ve distal vidaları revize edip, kemik grefti kullanarak kaynama elde ettiklerini belirttiler (beş hastaya otolog kemik grefti kullanılmış). Bu çalışmada değindikleri temel nokta, yeni bir implantın kaynamama alanında yeni bir stres yaratacağı, ek olarak vasküler desteğin bozulacağını; bu nedenle, tespitin revizyonu ve greftlemeyle birlikte kaynamanın elde edilebileceğiydi. Fakat, çalışmalarında \%57'lik bir kaynama oranı buldular ve tek başına plak revizyonun greftlemeyle birlikte tercih edilir bir tedavi şekli olmadığını belirttiler. ${ }^{[28]}$

Distal femur kırıklarındaki plak uygulamalarında, biyomekanik olarak yeterli bir plak tespiti ve beraberinde biyolojik iyileşmeyi hızlandırıcı bir greft uygulaması, günümüzde kabul gören bir yöntemdir (Şekil 1). Literatürde greft alternatifi olarak strut greftler, otogreftler, greft yedekleri ya da bunların karışımı sunulmuş olup, bu karar defektin boyutuna ve kırık biyolojisine göre belirlenmelidir. Yine, lateral plaklamanın mediyalden uygulanacak bir başka plakla desteklenmesi gereği, kırık stabilitesinin sağlanması açısından, seçilmiş olgularda tercih edilebilecek bir yöntemdir.

\section{İntramedüller Çivileme Uygulamaları}

Distal femur kaynamama olgularında IMÇ, diğer bir tedavi seçeneğidir (Şekil 2). Bu konuda ilk serilerden birinin sahibi olan Koval ve ark., retrograd intramedüller çivi (RiMÇ) ile tedavi ettikleri 16 hastanın sadece \%25'inde kaynama olduğunu belirttiler. ${ }^{[29]}$ Bu duruma zıt olarak Wu ve ark., antegrad çivileri retrograd olarak kullanıp dinamik kilitledikleri ve aynı taraf mediyal tibial kondilden elde ettikleri otolog kemik greftlerini kullandıkları 18 hastada \%88,9'luk bir kaynama oranı belirttiler. Fakat bu çalışmada, çivinin proksimal kilitlemesinin yapılabilmesi için distal parçanın $4 \mathrm{~cm}$ 'den uzun olması gerektiği belirtilmiştir. Bu bölgenin kaynamamalarında, kemik stoğunun ve kemik kalitesini kötü olması nedeniyle iMÇ'yi tercih etmekle birlikte; sağlık sigortası retrograd çivileri ödemediği için, antegrad çivileri kullandıklarını kaynamamanın esas tedavisinin implant tercihinden çok yerel vasküler beslenmenin korunması olduğunu; ama her halükarda, lateral yaklaşımla RiMÇ ile otolog greftlemenin tercih edilebilir ve sonuçları iyi bir tedavi şekli olduğunu belirtmişlerdir. ${ }^{[30]}$ Aynı yıl Chen ve ark., bir olgu sunumunda, distal femur kırığı nedeniyle lateralden yonca plakla osteosentez yapılan hastada gelişen kaynamamadan söz etmektedirler. Bu olguda, ilk revizyonda lateralden kilitli plak konulmuş ve otolog greftleme yapılmış. Bir yıl sonra plağın kırılmasıyla tekrar hastaneye başvuran hastaya, RiMÇ ile beraber, aynı taraf fibuladan alınan strut greft ikiye ayrılıp lateralden ve mediyalden konularak, iliak kanattan alınan kansellöz otogreftle greftlenmiş. Ameliyat sonrası 15. ayda tam kaynama elde edilmiş. ${ }^{[31]}$ Aynı şekilde Wu ve ark. diğer bir çalışmalarında, lateral kilitli plaklama sonrası kaynamama gelişen 21 hastada, retrograd kilitli iMÇ ile birlikte greftleme sonrasında \%100 kaynama bildirmişlerdir. Ayrıca, bu olgularda kaynamama hattındaki rotasyonel stabilite değerlendirilerek, instabil olduğu gözlenen sekiz hastada humeral destek plağıyla ek tespit sağlanmıştır. ${ }^{[32]}$

İntramedüller çivileme, plak osteosentez sonrası gelişen kaynamama olgularında kullanılabildiği gibi, bunun tam tersi de bir tedavi şekli olarak kullanılabilmektedir. Graves ve ark., Tip 3C açık distal femur kırığı sonrası RiMÇ yapılan bir olguda gelişen hipertrofik kaynamama olgusunu paylaşmışlardır. Bu olguda, kaynamama hattında daha önceki cerrahide yapılan damar onarımı sonrası oluşan intraosseöz anevrizma tespit edilmiş, ameliyat sırasında damar cerrahı tarafından onarım revize edilmiş ve sonrasında RiMÇ çıkarılarak, lateralden kilitli plak tespiti ve otolog greftleme yapılmış. Ameliyat sonrası 6 . ayda klinik ve radyolojik olarak tam kaynama olduğu bildirilmiş. ${ }^{[33]} \mathrm{Pao}$ ve ark., ikisi primer biri periprostetik kırık sonrası lateral plaklama yapılan ve sonrasında kaynamama gelişen üç olguda, plağı çıkarıp sonrasında RiMÇ yaparak kaynama elde ettiklerini bildirmişlerdir. ${ }^{[34]}$ Fakat bu iki çalışmada, kaynamama olgularından önce dikkat çekilmesi gereken konu, kırıkların başlangıç tedavisinde kullanılan plakların kısa olması ve tüm vida deliklerinin doldurulması gibi tespit yetersizliğine neden olabilecek uygulamaların varlığıdır.

\section{Plak Çivi Kombinasyonu}

Plak çivi kombinasyonu, ilerleyen zamanlarda başlı başına ayrı bir tedavi şekli olarak karşımıza çıkmaya başladı. Distal femur kaynamamaya özgün olmasa da, Birjandinejad ve ark. ile Nadkarni ve ark.'nın yaptığı çalışmalar kombine plak/çivi tedavileri için öncül teşkil etmişlerdir. ${ }^{[3,36]}$ Attum ve ark., kombine plak/iMÇ 

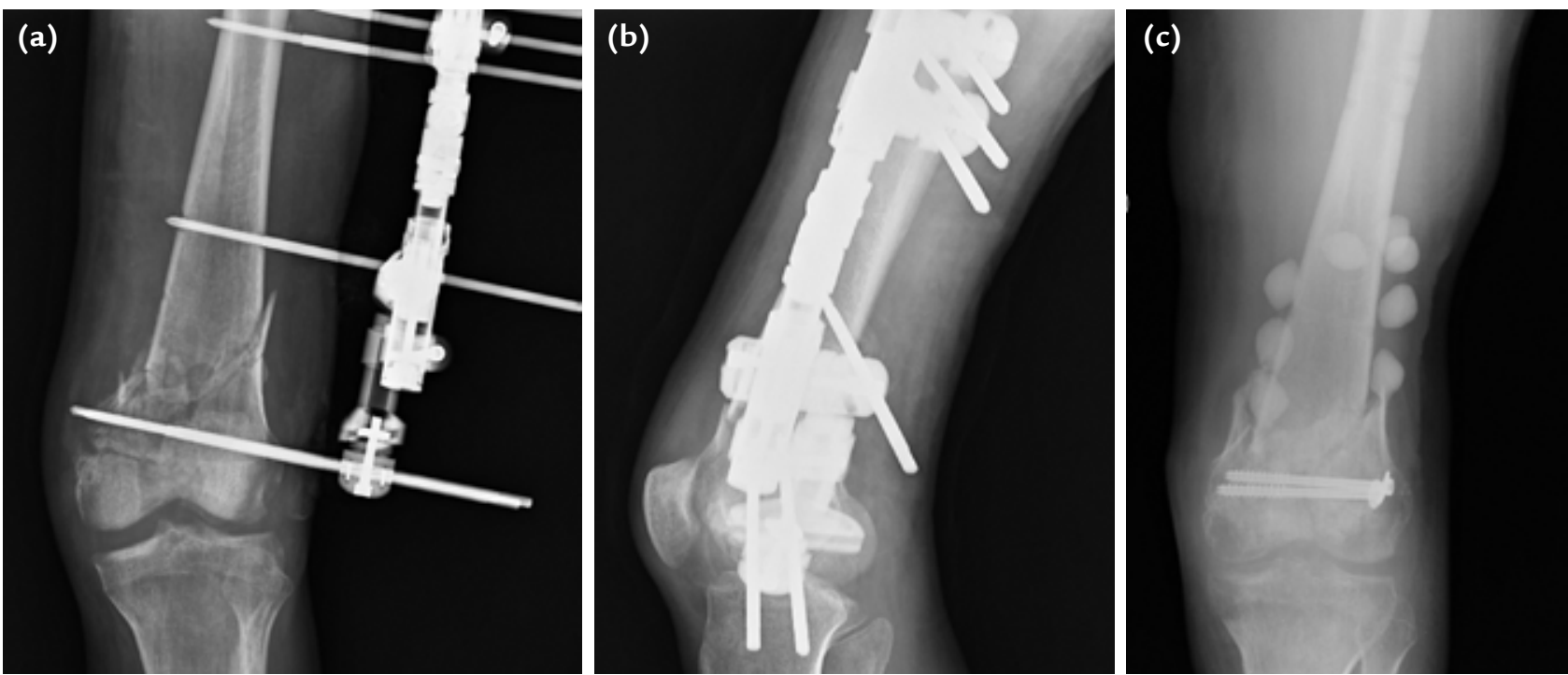
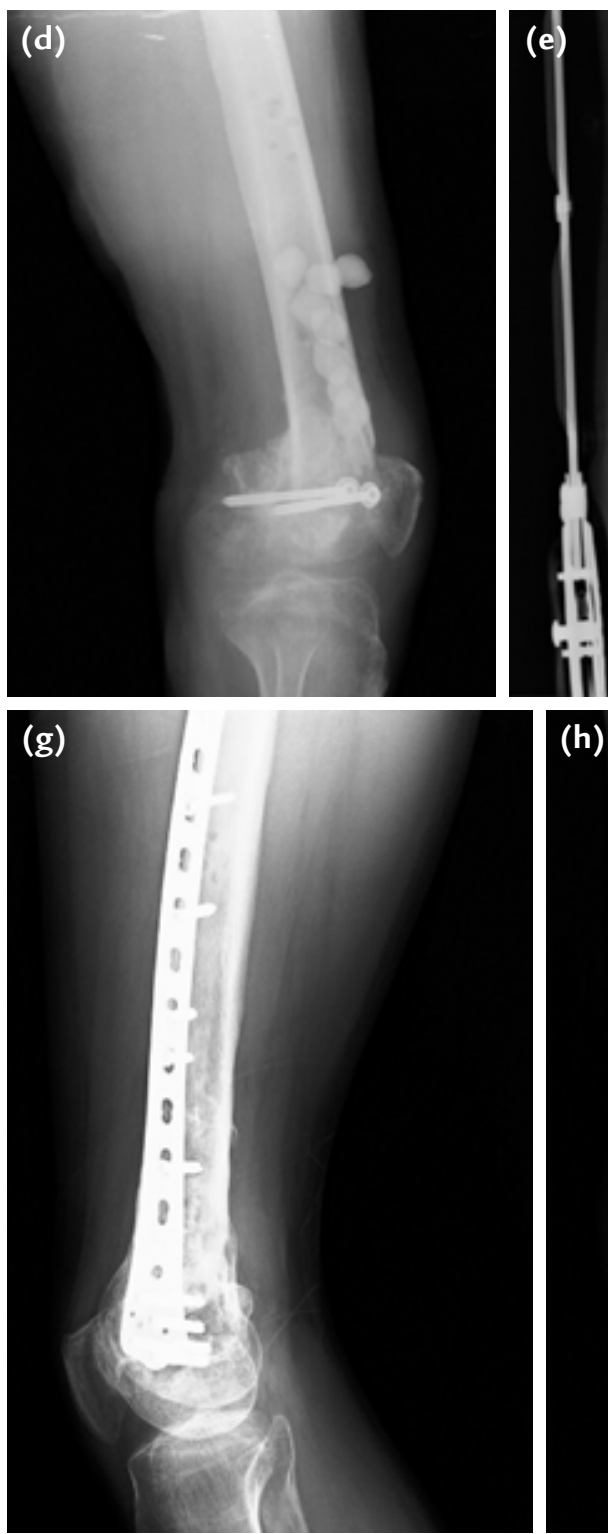

(h)

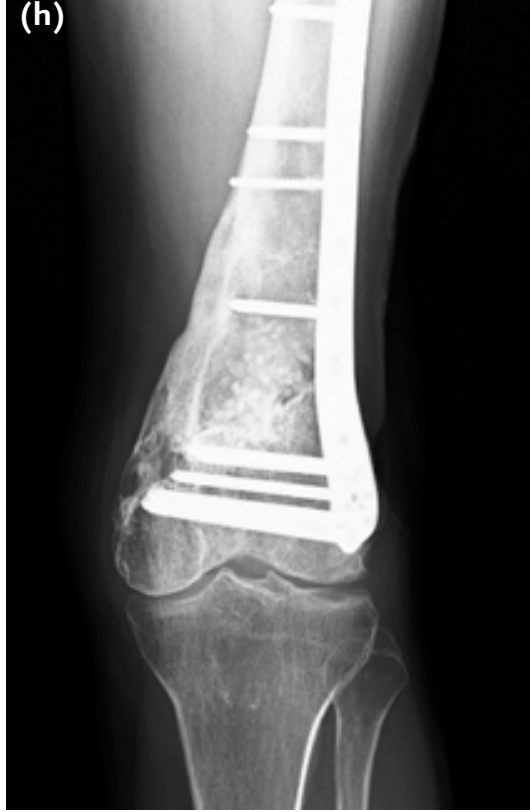

(f)

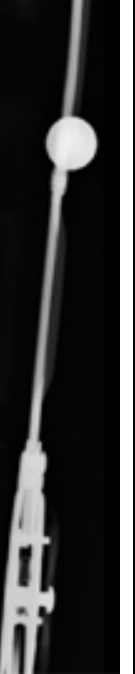

Şekil 1. a-h. Tip 3 açık distal femur kırıklı hastada eksternal tespit uygulaması $(\mathbf{a}, \mathbf{b})$. Hastanın eksternal tespit ile yeterli kaynaması görülmemiş fiksatör çıkarılıp minimal osteosentez uygulanıp antibiyotikli boncukla bir süre takip edilmiştir (c, d). Hastaya distal femoral plakla internal tespit uygulandı $(\mathbf{e}, \mathbf{f})$. Ameliyat sonrası 1. yıl kaynamış görüntüler $(\mathrm{g}, \mathrm{h})$. 

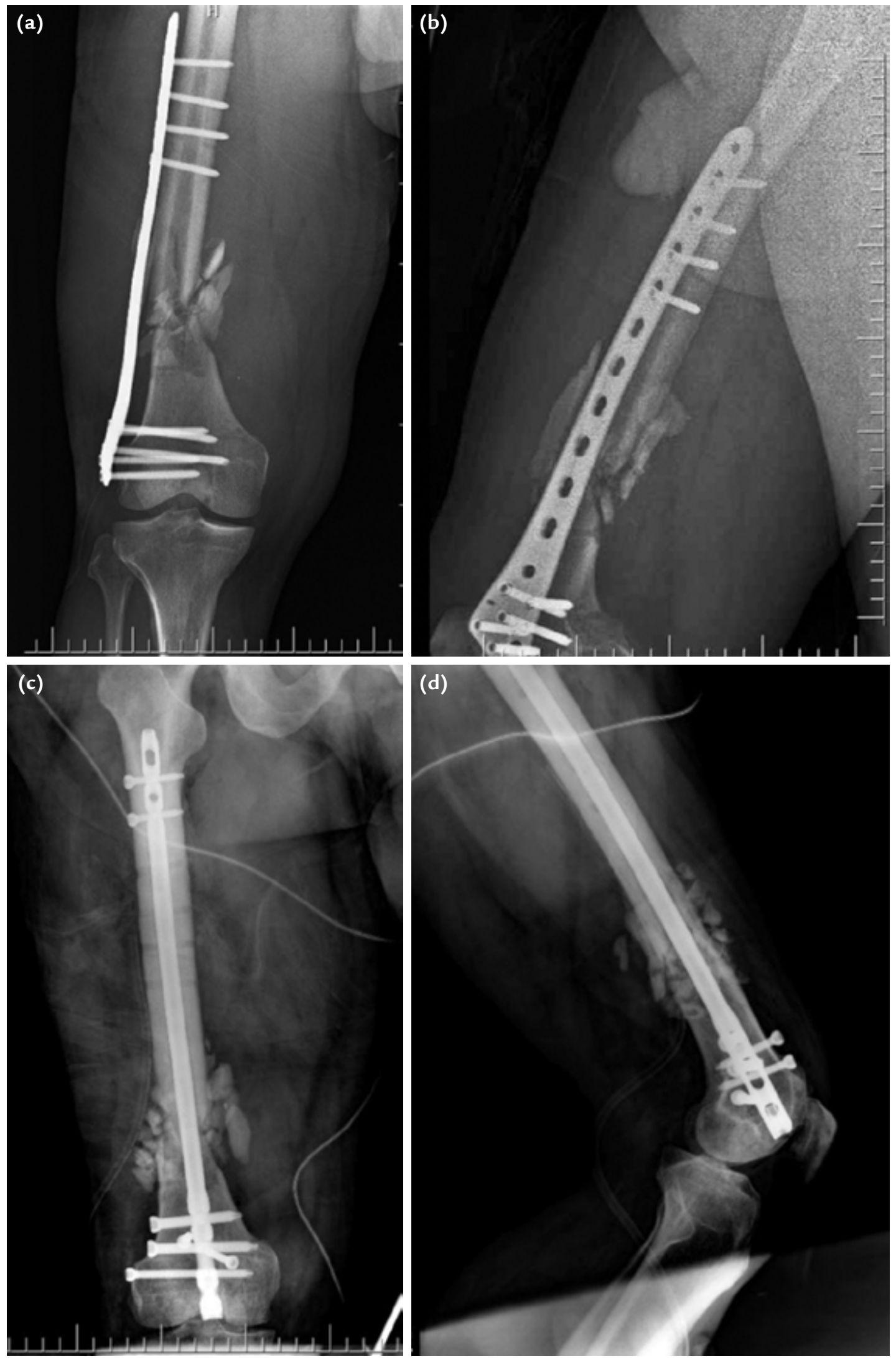

Şekil 2. a-d. Distal femur plak uygulaması sonrasında kaynamama (a, b). Hastaya plak çıkarımı sonrasında oymalı iMÇ uygulandı $(c, d)$. 
ile beraber ipsilateral femur remerizasyonuyla elde ettikleri otolog kemik greftini kullanarak tedavi ettikleri 22 hastanın geriye dönük olarak incelemesinde \%100 kaynama elde ettiklerini bildirdiler. Aynı çalışmada, sadece iki hastada enfeksiyon gördüklerini, bir hastada debridmanı gerektirecek derin enfeksiyonun olduğunu ve her iki enfeksiyonu da oral antibiyoterapiyle tedavi ettiklerini ifade ettiler. Bu teknikle, hem kaynama için gerekli stabilizasyonu hem de deformite düzeltilmesinin bir arada daha az morbidite oluşturularak elde edilebileceğini belirttiler. ${ }^{[37]}$

\section{Eksternal Tespit Uygulamaları}

Özellikle enfekte ve/veya uzuvlar arası uzunluk farkı olan kaynamama olgularında, eksternal tespit diğer bir tedavi modalitesi olarak karşımıza çıkmaktadır. Ali ve ark., 15 hastanın dahil olduğu çalışmalarında, bu hastaların 14'ünde $(\% 93,3)$ kaynama bildirdiler. ${ }^{[38]}$ Teknik olarak, kaynamama sahasında monolateral fiksatör kullandıklarını, 12 hastada distal parçanın küçük olması nedeniyle bu parçanın tespiti için diz eklemini geçen fiksatör sistemi kurduklarını ve eksternal fiksatörle beraber açısal deformiteyi ve eş zamanlı olarak uzunluk problemlerini düzeltebildiklerini; fakat diz ekleminde eklem hareket açıklığı kaybının bir sonuç olarak karşılarına çıktığını ifade ettiler. ${ }^{[38]}$ Saridis ve ark., kurtarma işlemi olarak Ilizarov metoduyla tedavi ettikleri enfekte ve kemik defekti olan 13 hastayı geriye dönük olarak incelediklerinde, tüm hastalarda kaynama elde ettiklerini bildirdiler. ${ }^{[39]}$ Başlangıç tedavisi olarak; bu hastaların beşine açık redüksiyon internal tespit, yedisine unilateral transartiküler eksternal tespit ve bir hastaya da hibrid eksternal tespit yapılmış. Hastaların 10'una bifokal kombine kompresyon-distraksiyon osteosentez, üçüne de bifokal ardışık distraksiyon-kompresyon osteosentezi yapılmış. Sekiz hastaya ek müdahalelerde bulunulsa da, tam kaynama elde edildiğinde hastaların tam yük verebildikleri ve günlük aktivitelerini sorunsuzca yapabildikleri bir uzva sahip olduklarını belirtmişlerdir. Bu tekniğin, kalan kemik stoğunun vaskülaritesinin yumuşak dokuya fazla zarar vermeden korunması, kısalmanın ve aşırı dizilim bozukluğunun önüne geçilebilmesi nedeniyle, tercih edilebilir ve önemli bir tedavi seçeneği olduğunu belirtmişlerdir.

\section{Kurtarma Prosedürleri}

Diz replasman cerrahisi, distal femur kaynamama olgularında özellikle kurtarma işlemi olarak tercih edilebilmektedir. Özellikle yaşlı, ciddi osteopenisi olan, kemik stoğu kötü, daha önce başarısızlıkla sonuçlanmış ve/veya diz ekleminde ciddi artrozu olan hastalarda, artroplasti bir seçenek olarak karşımıza çıkmaktadır. ${ }^{[40]}$ Kress ve ark., total diz artroplastisiyle tedavi ettikleri iki suprakondiler kaynamama hastasının altı ay içerisinde iyileştiğini ve HSS (Hospital for Special Surgery) diz skorlarında artış olduğunu belirttiler. ${ }^{[41]}$ Haidukewych ve ark., distal femur kaynamama nedeniyle 17 hastayı opere ettiklerini; \%91 oranında beş yıllık sağkalımları ve $\% 29$ oranında ameliyat sırası ve sonrasında komplikasyonları olduğunu belirttiler. Her ne kadar cerrahi açıdan ciddi zorluklar içerse de, replasman cerrahisi yapılan hastaların büyük bir çoğunluğunda, primer total diz protezi yapılan hastalara kıyasla daha az olmakla birlikte, ciddi ağrı palyasyonu ve fonksiyonel ilerleme kaydettiklerini ifade ettiler. ${ }^{[40]}$ Davila ve ark., tümör proteziyle tedavi ettikleri iki distal femur kaynamama hastasının iki yıl içerisinde tam yük verebildiklerini, HSS skorlarının arttığını ve $0-100^{\circ}$ fleksiyona sahip olduklarını belirterek, megaprotezlerin bir kurtarma işlemi olarak kullanılabileceğini belirttiler. ${ }^{[42]}$ Vaisya ve ark., enfekte olmayan sekiz distal femur kaynamama hastasını megaprotezle tedavi ettiklerini ve tüm hastalarda tatmin edici sonuçlara ulaştıklarını ifade ettiler. Özellikle erken mobilizasyonun ve günlük yaşama dönüşün bu tekniği öne çıkardığını belirttiler.[43]

Peki, destek tedavisi şeklindeki tedavilerle de kaynama sağlanabilir mi? Waseem ve ark. 2010 yılında, 77 yaşında motorlu taşıt kazası sonrası bilateral suprakondiler femur kırığı sebebiyle opere edilen bir kadın hastada gelişen bilateral kaynamama olgusunu sundular. Bu olguda, sol tarafa bir kez, sağ tarafa ise iki kez cerrahi müdahale uygulanmasına rağmen kaynamamanın tedavi edilemediğini, ilk cerrahiden 19 ay sonra başka bir merkezde başlanan düşük-yoğunluklu pulse ultrasonografi tedavisi sonrası 8 . ayda her iki tarafta da kaynama olduğunu bildirdiler. ${ }^{[4]}$ Literatürde, bu tür destek tedavileriyle alakalı ve özellikle distal femur kaynamamayı konu alan başka herhangi bir çalışma bulunmamaktadır.

Yukarıda, literatürdeki mevcut çalışmalarla da ifade ettiğimiz üzere, distal femur kaynamamanın belli bir tedavi algoritması mevcut bulunmamaktadır. Kırığın primer özellikleri, başlangıç tedavisinin çeşidi ve hastanın komorbid durumları, her kaynamama olgusunu kendi içerisinde yeterince karmaşık bir hale getirmektedir. Ayrıca, hastanın beklentisi ve tedavi sürecine uyumu da tedavi şeklinin seçimi ve tedavinin sonuçlarını etkilemektedir. Distal femur kaynamama olgularında, öncellikle kaynamamaya neyin neden olduğunu anlamaya çalışarak buna uygun tedavi şeklinin, gerekirse destek tedavilerinin de eklenerek belirlenmesi ve hastaya özgü obezite, sigara kullanımı vb. durumların minimize edilmesi, bu denli tedavisi zor ve karmaşık olgularda başarılı sonuçlara ulaşılmasını sağlayacaktır. 


\section{KAYNAKLAR}

1. Gwathmey WF Jr, Jones-Quaidoo SM, Kahler D, Hurwitz S, Cui Q. Distal femoral fractures: current concepts. J Am Acad Orthop Surg 2010;18(10):597-607. Crossref

2. Gangavalli AK, Nwachuku CO. Management of Distal Femur Fractures in Adults: An Overview of Options. Orthop Clin North Am 2016;47(1):85-96. Crossref

3. Fakler JKM, Ponick C, Edel M, Mobius R, Brand AG, Roth A, Josten C, Zajonz D. A new classification of TKA periprosthetic femur fractures considering the implant type. BMC Musculoskelet Disord 2017;18(1):490. Crossref

4. Nauth A, Ristevski B, Begue T, Schemitsch EH. Periprosthetic distal femur fractures: current concepts. J Orthop Trauma 2011;25 Suppl 2:S82-5. Crossref

5. Kellam JF, Meinberg EG, Agel J, Karam MD, Roberts CS. Introduction: Fracture and Dislocation Classification Compendium-2018. J Orthop Trauma 2018;32 Suppl 1:S110. Crossref

6. Beltran MJ, Gary JL, Collinge CA. Management of distal femur fractures with modern plates and nails: state of the art. J Orthop Trauma 2015;29(4):165-72. Crossref

7. Ricci WM, Streubel PN, Morshed S, Collinge CA, Nork SE, Gardner MJ. Risk factors for failure of locked plate fixation of distal femur fractures: an analysis of 335 cases. J Orthop Trauma 2014;28(2):83-9. Crossref

8. Ehlinger M, Ducrot G, Adam P, Bonnomet F. Distal femur fractures. Surgical techniques and a review of the literature. Orthop Traumatol Surg Res 2013;99(3):353-60. Crossref

9. Southeast Fracture Consortium. LCP Versus LISS in the Treatment of Open and Closed Distal Femur Fractures: Does it Make a Difference? J Orthop Trauma 2016;30(6):e212-6. Crossref

10. Moloney GB, Pan T, Van Eck CF, Patel D, Tarkin I. Geriatric distal femur fracture: Are we underestimating the rate of local and systemic complications? Injury 2016;47(8):1732-6. Crossref

11. Bellabarba C, Ricci WM, Bolhofner BR. Indirect reduction and plating of distal femoral nonunions. J Orthop Trauma 2002;16(5):287-96. Crossref

12. Henderson CE, Kuhl LL, Fitzpatrick DC, Marsh JL. Locking plates for distal femur fractures: is there a problem with fracture healing? J Orthop Trauma 2011;25 Suppl 1:S8-14. Crossref

13. Henderson CE, Lujan TJ, Kuhl LL, Bottlang M, Fitzpatrick DC, Marsh JL. 2010 mid-America Orthopaedic Association Physician in Training Award: healing complications are common after locked plating for distal femur fractures. Clin Orthop Relat Res 2011;469(6):1757-65. Crossref

14. Hoffmann MF, Jones CB, Sietsema DL, Tornetta P 3rd, Koenig SJ. Clinical outcomes of locked plating of distal femoral fractures in a retrospective cohort. J Orthop Surg Res 2013;8(1):43. Crossref

15. Rodriguez EK, Zurakowski D, Herder L, Hall A, Walley KC, Weaver MJ, Appleton PT, Vrahas M. Mechanical Construct Characteristics Predisposing to Non-union After Locked Lateral Plating of Distal Femur Fractures. J Orthop Trauma 2016;30(8):403-8. Crossref

16. Lujan TJ, Henderson CE, Madey SM, Fitzpatrick DC, Marsh $\mathrm{JL}$, Bottlang M. Locked plating of distal femur fractures leads to inconsistent and asymmetric callus formation. J Orthop Trauma 2010;24(3):156-62. Crossref

17. Canadian Orthopaedic Trauma Society. Are Locking Constructs in Distal Femoral Fractures Always Best? A Prospective Multicenter Randomized Controlled Trial Comparing the Less Invasive Stabilization System With the Minimally Invasive Dynamic Condylar Screw System. J Orthop Trauma 2016;30(1):e1-6. Crossref
18. Vallier HA, Immler W. Comparison of the 95-degree angled blade plate and the locking condylar plate for the treatment of distal femoral fractures. J Orthop Trauma 2012;26(6):32732. Crossref

19. Ebraheim NA, Martin A, Sochacki KR, Liu J. Nonunion of distal femoral fractures: a systematic review. Orthop Surg 2013;5(1):46-50. Crossref

20. Gardner MJ, Toro-Arbelaez JB, Harrison M, Hierholzer C, Lorich DG, Helfet DL. Open reduction and internal fixation of distal femoral nonunions: long-term functional outcomes following a treatment protocol. J Trauma 2008;64(2):434-8. Crossref

21. Monroy A, Urruela A, Singh P, Tornetta P 3rd, Egol KA. Distal femur nonunion patients can expect good outcomes. J Knee Surg 2014;27(1):83-8. Crossref

22. Chapman MW, Finkemeier CG. Treatment of supracondylar nonunions of the femur with plate fixation and bone graft. J Bone Joint Surg Am 1999;81(9):1217-28. Crossref

23. Bellabarba C, Ricci WM, Bolhofner BR. Results of indirect reduction and plating of femoral shaft nonunions after intramedullary nailing. J Orthop Trauma 2001;15(4):25463. Crossref

24. Wang JW, Weng LH. Treatment of distal femoral nonunion with internal fixation, cortical allograft struts, and autogenous bone-grafting. J Bone Joint Surg Am 2003;85(3):436-40. Crossref

25. Kanakeshwar RB, Jayaramaraju D, Agraharam D, Rajasekaran $\mathrm{S}$. Management of resistant distal femur non-unions with allograft strut and autografts combined with osteosynthesis in a series of 22 patients. Injury 2017;48 Suppl 2:S14-7. Crossref

26. Amorosa LF, Jayaram PR, Wellman DS, Lorich DG, Helfet DL. The use of the 95-degree-angled blade plate in femoral nonunion surgery. Eur J Orthop Surg Traumatol 2014;24(6):953-60. Crossref

27. Holzman MA, Hanus BD, Munz JW, O'Connor DP, Brinker MR. Addition of a Medial Locking Plate to an In Situ Lateral Locking Plate Results in Healing of Distal Femoral Nonunions. Clin Orthop Relat Res 2016;474(6):1498-505. Crossref

28. Ebraheim NA, Buchanan GS, Liu X, Cooper ME, Peters N, Hessey JA, Liu J. Treatment of Distal Femur Nonunion Following Initial Fixation with a Lateral Locking Plate. Orthop Surg 2016;8(3):323-30. Crossref

29. Koval KJ, Seligson D, Rosen H, Fee K. Distal femoral nonunion: treatment with a retrograde inserted locked intramedullary nail. J Orthop Trauma 1995;9(4):285-91. Crossref

30. Wu CC. Retrograde dynamic locked nailing for aseptic nonunion of femoral supracondyle after antegrade locked nailing. Arch Orthop Trauma Surg 2011;131(4):513-7. Crossref

31. Chen X, Li JJ, Kong Z, Yang DX, Yuan XN. Autologous grafts of double-strut fibular cortical bone plate to treat the fractures and defects of distal femur: a case report and review of literature. Chin J Traumatol 2011;14(4):241-6.

32. Wu CC. Retrograde locked intramedullary nailing for aseptic supracondylar femoral nonunion following failed locked plating. J Orthop Surg (Hong Kong) 2015;23(2):155-9. Crossref

33. Graves ML, Ryan JE, Mast JW. Supracondylar femur nonunion associated with previous vascular repair: importance of vascular exam in preoperative planning of nonunion repair. J Orthop Trauma 2005;19(8):574-7. Crossref

34. Pao JL, Jiang CC. Retrograde intramedullary nailing for nonunions of supracondylar femur fracture of osteoporotic bones. J Formos Med Assoc 2005;104(1):54-9. 
35. Nadkarni B, Srivastav S, Mittal V, Agarwal S. Use of locking compression plates for long bone nonunions without removing existing intramedullary nail: review of literature and our experience. J Trauma 2008;65(2):482-6. Crossref

36. Birjandinejad A, Ebrahimzadeh $\mathrm{MH}$, Ahmadzadeh-Chabock $\mathrm{H}$. Augmentation plate fixation for the treatment of femoral and tibial nonunion after intramedullary nailing. Orthopedics 2009;32(6):409-12. Crossref

37. Attum B, Douleh D, Whiting PS, White-Dzuro GA, Dodd AC, Shen MS, Mir HR, Obremskey WT, Sethi MK. Outcomes of Distal Femur Nonunions Treated With a Combined Nail/ Plate Construct and Autogenous Bone Grafting. J Orthop Trauma 2017;31(9):e301-4. Crossref

38. Ali F, Saleh M. Treatment of distal femoral nonunions by external fixation with simultaneous length and alignment correction. Injury 2002;33(2):127-34. Crossref

39. Saridis A, Panagiotopoulos E, Tyllianakis M, Matzaroglou C, Vandoros N, Lambiris E. The use of the llizarov method as a salvage procedure in infected nonunion of the distal femur with bone loss. J Bone Joint Surg Br 2006;88-B(2):232-7. Crossref
40. Haidukewych GJ, Springer BD, Jacofsky DJ, Berry DJ. Total knee arthroplasty for salvage of failed internal fixation or nonunion of the distal femur. J Arthroplasty 2005;20(3):3449. Crossref

41. Kress KJ, Scuderi GR, Windsor RE, Insall JN. Treatment of nonunions about the knee utilizing custom total knee arthroplasty with press-fit intramedullary stems. J Arthroplasty 1993;8(1):49-55. Crossref

42. Davila J, Malkani A, Paiso JM. Supracondylar distal femoral nonunions treated with a megaprosthesis in elderly patients: a report of two cases. J Orthop Trauma 2001;15(8):574-8. Crossref

43. Vaishya R, Singh AP, Hasija R, Singh AP. Treatment of resistant nonunion of supracondylar fractures femur by megaprosthesis. Knee Surg Sports Traumatol Arthrosc 2011;19(7):1137-40. Crossref

44. Waseem Z, Ford M, Syed K, Flannery J. Chronic nonunion in a patient with bilateral supracondylar distal femur fractures treated successfully with twice daily low-intensity pulsed ultrasound. PM R 2010;2(2):159-61. Crossref 